de Gruyter Lehrbuch 



\title{
Schuldrecht
}

von

\section{Wolfgang Fikentscher}

\author{
8., neubearbeitete Auflage
}

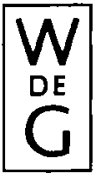

1992

Walter de Gruyter · Berlin · New York 
Dr. jur. Wolfgang Fikentscher, LL. M. (Michigan)

o. Professor an der Ludwig-Maximilians-Universität München,

Vorstand des Instituts für Internationales Recht,

des Instituts für Handels-, Wirtschafts- und Arbeitsrecht und des Instituts

für Gewerblichen Rechtsschutz und Urheberrecht (stellv. Geschäftsführer),

Auswärtiges Mitglied des Max-Planck-Instituts für ausländisches und

internationales Patent-, Urheber- und Wettbewerbsrecht, München.

(@) Gedruckt auf säurefreiem Papier, das die US-ANSI-Norm über Haltbarkeit erfüllt.

Die Deutsche Bibliothek - CIP-Einheitsaufnahme

Fikentscher, Wolfgang:

Schuldrecht / von Wolfgang Fikentscher. - 8, neubearb. Aufl.

- Berlin ; New York : de Gruyter, 1991

(De-Gruyter-Lehrbuch)

ISBN 3-11-013191-9 Sn.

ISBN 3-11-013190-0 Gewebe

(C) Copyright 1991 by Walter de Gruyter \& Co., D-1000 Berlin 30.

Dieses Werk einschließlich aller seiner Teile ist urheberrechtlich geschützt. Jede Verwertung außerhalb der engen Grenzen des Urheberrechtsgesetzes ist ohne Zustimmung des Verlages unzulässig und strafbar. Das gilt insbesondere für Vervielfältigungen, Übersetzungen, Mikroverfilmungen und die Einspeicherung und Verarbeitung in elektronischen Systemen.

Printed in Germany.

Satz und Druck: Saladruck, D-1000 Berlin

Bindearbeiten: Lüderitz \& Bauer GmbH, D-1000 Berlin 61 